\title{
educação

\section{Sentidos atribuídos ao significante prática curricular nas produções científicas da ANPEd}

\author{
Maria Júlia Carvalho de Melor, Lucinalva \\ Andrade Ataíde de Almeida ${ }^{\mathrm{II}}$ \\ Universidade Federal de Pernambuco, Brasil
}

\author{
Carlinda Leite ${ }^{\text {III }}$ \\ Universidade do Porto, Portugal
}

\begin{abstract}
O artigo inscreve-se no debate sobre o currículo, e mais especificamente sobre as práticas curriculares, e tem como objetivo identificar sentidos atribuídos ao significante prática curricular nas produções científicas da ANPEd (Associação Nacional de Pós-Graduação e Pesquisa em Educação), Brasil. Para isso, mobiliza conceitos de currículo que o compreendem como projeto formativo produzido pelas políticas e pelos agentes educativos que o configuram e praticam nos quotidianos escolares, reconhecendo-o como território de disputas. Neste sentido, foram selecionadas e analisadas, a partir da Teoria do Discurso de Ernesto Laclau e Chantal Mouffe, as pesquisas circunscritas ao período de 2006-2015. Essa análise permitiu identificar uma articulação da prática curricular com outros significantes, configuradora de sentidos que reconhecem os quotidianos das escolas como espaços de criação e recriação curriculares, e que perspetivam os professores como intelectuais responsáveis pela organização do processo didático-pedagógico, isto é, como profissionais capazes de criarem conhecimentos que respondam às urgências sentidas pelo exercício da docência mas que não se enquadram necessariamente nos modelos determinados pelas políticas curriculares.
\end{abstract}

Palavras-chave: Sentidos; Currículo; Prática Curricular; Teoria do Discurso

\section{N T RO D U Ç Ã O}

O artigo insere-se no debate sobre o currículo, e mais especificamente sobre as práticas curriculares, e elege como objeto de estudo os movimentos de criação e recriação da prática curricular de professores da educação básica, a partir das relações com a prática coletiva.
Partindo de uma compreensão de currículo enquanto projeto formativo produzido pelas políticas e pelos agentes educativos que o configuram e praticam nos quotidianos escolares, reconhece-se que o currículo, enquanto território de disputas (Arroyo, 2013), "é instrumento essencial para a compreensão das políticas curriculares que dão as diretrizes 
de cada instituição" (Carmo \& Almeida, 2014, p. 25).

Sendo o currículo planeado parte integrante de políticas, ele é, por outro lado, resultado das ressignificações dessas políticas nos contextos escolares (Leite, Fernandes, \& Mouraz, 2014). Ou seja, as proposições das políticas não são assumidas pelas instituições educativas sem um processo de apropriação que as ressignifica a partir das suas próprias conceções e das necessidades que emergem da prática pedagógica desenvolvida nessas instituições e sobre as quais pretendem atuar. É este poder de agência (Priestley, 2011; Priestley, Biesta, \& Robinson, 2015) que é reconhecido aos professores e que os torna decisores e construtores do currículo, em vez de meros consumidores de currículos prescritos pelas políticas de educação à escala nacional (Leite \& Fernandes, 2010). Clarificando o entendimento que estamos a fazer de currículo, podemos referir que ele se encontra na intermediação entre o que é proposto pelas políticas e o que é ressignificado na prática (Moreira, 2001), sendo também projeto formativo, prática produtiva de construção e socialização do conhecimento e de disputa de poder, ou seja, "vemos o currículo não como um conceito, mas como um conjunto de práticas entrecruzadas, desenvolvidas por sujeitos que ao mesmo tempo em que produzem e discursam sobre o currículo são também formados por ele" (Silva \& Almeida, 2013, pp. 105-106).

É tendo por referência estas ideias que no presente artigo superamos a dicotomia entre aquilo que é pensado e aquilo que é vivido (Ferraço \& Nunes, 2012), ou seja, captamos o currículo na sua complexidade, na articulação entre o que é prescrito e a sua reinvenção na prática. Esta conceção de currículo, como instrumento de formação (Pacheco, 2005), pressupõe compreender os contextos, os atores e as intenções que o orientam, deixando, portanto, de ser uma coisa ou outra para se constituir enquanto elemento híbrido das teoriaspráticas curriculares (Ferraço \& Nunes, 2012; Gonçalves, 2017).

Em linha com o que até aqui sustentamos, o que compreendemos por currículo tem uma vinculação ao que corresponde à prática curricular. Partindo deste entendimento, o estudo de que dá conta este artigo analisa os sentidos atribuídos ao significante ${ }^{1}$ prática curricular nas produções científicas da ANPEd (Associação Nacional de Pós-Graduação e Pesquisa em Educação), para perceber o papel desse locus na centralidade que assume na produção de conhecimento ao nível da pósgraduação no Brasil. Para isso, escolheramse as pesquisas apresentadas neste evento no período de 10 anos compreendido entre 20062015. A escolha desse período justifica-se, por um lado, por entendermos que o conhecimento produzido nos últimos anos apresenta-nos um quadro recente dos sentidos fabricados sobre a prática curricular, e, por outro, por considerarmos que, para o aprofundamento de qualquer temática, é necessária a análise de um período relativamente extenso, para que seja possível a demarcação das diferenças, semelhanças, criações, recriações ou retorno aos dizeres já ditos nesse processo de fabricação de sentidos.

Frente a esse marco temporal, selecionámos, lemos na íntegra e analisámos as pesquisas a partir de um olhar fundado na Teoria do Discurso (Laclau \& Mouffe, 1987), a qual apresenta a consciência dos limites da razão, ou seja, percebe o caráter precário e contingente de toda a objetividade e a relatividade dos valores

\footnotetext{
${ }^{1}$ Entendemos significante como a parte concreta dos signos; no nosso caso, os significantes são as práticas coletiva e curricular, onde a partir deles buscamos a polissemia dos significados/sentidos que carregam, ou seja, as ideias que estão associadas aos signos. Nesse sentido, compreendemos que um mesmo significante pode ter vários significados/sentidos.
} 
e construções teóricas. Dito de outra forma, consideramos que "se hay algo que domina el clima intelectual de las últimas décadas, es una nueva, creciente y generalizada consciencia de los límites" (Laclau \& Mouffe, 2000, p. 19). De facto, a nossa análise teve em consideração essa consciência dos limites e inscreve-nos no entendimento da impossibilidade de fixação total dos sentidos e na compreensão de que haverá sempre algo que fugirá à nossa racionalização. Esse algo que nos escapa configura-se como a possibilidade do dizer novo que ainda será fabricado em outro tempo histórico, por sujeitos que apresentam outras marcas pessoais e profissionais que influenciam as suas produções discursivas. É no quadro deste referencial analítico que se situa a interpretação dos discursos relativos às pesquisas que constituem a componente empírica do estudo a que se reporta este artigo.

\section{EFEITOS DE SENTIDOS ENTRE OS SIGNIFICANTES CURRÍCULO E PRÁTICA CURRICULAR: RELAÇões DE INTERDEPENDÊNCIA NO PROCESSO DE S I G N I F I C A Ç ÃO}

Conforme já sinalizámos, o que entendemos por currículo tem vinculação direta com a prática curricular, ou seja, o sentido de currículo que nos orienta determina o sentido de prática curricular, entendendo que ela é configuradora do currículo vivido. Como se infere, se compreendêssemos o currículo apenas como a descrição da trajetória escolar e do conjunto das disciplinas que devem ser ensinadas (presente na perspetiva religiosa de Calvino e em conceções tradicionais de currículo), atribuindo aos professores a responsabilidade de garantir que esse percurso é fielmente percorrido, teríamos uma compreensão de prática curricular como aplicação dessa trajetória, ou seja, os professores seriam meros aplicadores do que por outros é prescrito. Clarificando o que estamos a sustentar, nessa conceção existe uma ligação entre currículo e uma ordem estrutural delimitada e pré-definida, onde desvios não são permitidos. Este entendimento do currículo, enquanto delineador de um caminho único, parte da ideia de que a rigidez para trilhá-lo garantiria que todos aprendessem, e ao mesmo tempo, os mesmos conhecimentos.

Se, em vez dessa conceção, partíssemos de uma perspetiva técnica de conceber a escola e a educação, definiríamos o currículo como plano formal de organização da aprendizagem "num contexto organizacional, previamente planificado, a partir de finalidades e com a determinação de condutas precisas, através da formulação de objectivos" (Pacheco, 2005, p. 31) comportamentais. Nesta orientação técnica, o currículo é apresentado aos professores "de tal modo estruturado que lhes deixa margem apenas para pôr em prática o que outros delinearam" (Leite, Gomes, \& Fernandes, 2001, p. 15). Essa conceção, fortemente marcada pelas teorias de aprendizagem behavioristas, teria como consequência a delimitação do conceito de prática curricular enquanto processo construído em função dos objetivos previstos e traduzidos em desempenhos observáveis, de igual modo, em todos os alunos. Subjacente a este entendimento está a lógica de eficiência que prevê uma estruturação rígida em que tudo é planeado ao detalhe, não deixando abertura para a incorporação na prática do que não foi previsto. $\mathrm{O}$ que se deseja, neste entendimento do currículo, é a concretização dos objetivos previamente e detalhadamente definidos, seguindo uma série de passos que conduzirão à preparação das crianças e dos jovens para uma vida adulta anteriormente moldada. Nesta orientação, a prática curricular dos professores refere-se ao estabelecimento de objetivos e ao seu cumprimento rígido, desconsiderando a possibilidade de repensar esses objetivos no 
decorrer da vivência do currículo praticado.

Contrariamente a estas perspetivas, se nos orientarmos por uma conceção de currículo, que o pensa enquanto prática emancipatória, vê-lo-emos, quer como "o conjunto das experiências educativas vividas pelos alunos, dentro do contexto escolar, dependentes de intenções prévias, quer como um propósito bastante flexível, que permanece aberto e dependente das condições de sua aplicação" (Pacheco, 2005, p. 33). Nesta perspetiva, não existe uma separação entre os processos de conceção e de desenvolvimento do currículo, "uma vez que não existe distinção nítida entre a sua elaboração e a sua concretização, ou seja, o currículo constrói-se à medida que se vai desenvolvendo" (Leite, 2002, p. 88). Desse modo, a prática curricular assume a "instituição escolar como espaço social de relações e de desenvolvimento de estratégias plurais" (p. 88), o que se articula com o nosso sentido de currículo em linha com a prática curricular.

Aprofundando o conceito que nos orienta, entendemos o currículo como resultado das políticas curriculares, e reconhecemos que estas estão inseridas num processo de globalização com características neoliberais, isto é, percebemos o currículo como projeto que visa formar os sujeitos da escola, mas que é determinado pelo período social e histórico no qual se insere, sendo ainda resultado da interpretação daqueles que o vivenciam. Esta conceção corresponde a uma outra compreensão da prática curricular que será por nós encarada como o currículo em uso, isto é, como projeto educativo vivido, que, apesar de apresentar objetivos previamente definidos, se abre para as incertezas da prática. Além disso, ao considerar que o currículo é interpretado por aqueles que o vivenciam, vemos o professor como o sujeito privilegiado dessa interpretação, como aquele que o pratica quotidianamente em sala de aula e em outros espaços de formação e o reinventa a partir das necessidades que avalia como sendo importantes. Assim, a prática curricular que concebemos diz respeito a uma experiência que sofre influências das políticas curriculares globais e locais, mas que é igualmente uma experiência de criação e recriação do professor.

Em síntese, o currículo, como projeto formativo, como articulação entre as políticas e as práticas, como elemento vivenciado numa prática institucional, e mais especificamente na prática docente, é materializado nas práticas curriculares, ou seja, nas práticas encontradas a partir dos conhecimentos dos professores e dos conhecimentos que eles mobilizam na sua atuação profissional, bem como nos seus fazeres docentes (Tardif, 2002).

Desta forma, compreendemos que os professores são autores das práticas curriculares, uma vez que "promovem processos mediadores de captação e assimilação crítica das necessidades do ensino e da formação dos alunos, no complexo contexto contemporâneo, e que transpõem para as suas práticas curriculares na sala de aula" (Hagemeyer, 2006, cit. por Hagemeyer, 2011, p. 233). É nesse movimento de mediação que os professores criam e recriam o currículo, uma vez que traduzem o conhecimento veiculado nas suas salas de aula e nos seus fazeres docentes, produzindo ainda modos de ser e estar dos sujeitos aprendentes. É tendo esta ideia por referência que corroboramos Moreira (1995) quando se refere à "criação de condições, na prática curricular, que propiciem o fortalecimento do poder do/a professor/a" (p. 12), sem desconsiderar que a sua atuação estabelece relações com as demais práticas desenvolvidas pelos diversos sujeitos que fazem parte da escola. Ou seja, apesar de considerarmos ser este o sujeito privilegiado da prática curricular, ele não pratica um 
currículo ou currículos isoladamente, mas integra uma organização (a escola) na qual sobressai a "interação entre as pessoas, para a promoção da formação humana" (Libâneo, 2003, p. 316) ${ }^{2}$.

Dito de outro modo, consideramos que, apesar de haver o elemento de criação do professor na vivência de um currículo, ele precisa atender às exigências de uma gestão, às expectativas dos alunos, e ainda cumprir o que as políticas curriculares estipulam para o nível de ensino em que exerce a docência. Neste sentido, acaba por criar práticas articulatórias entre as diferentes práticas, o que resulta na mudança da sua própria prática curricular, uma vez que "articulação implica a construção de uma nova síntese, na qual a recomposição dos fragmentos é artificial, contingente. Ela não repõe uma unidade orgânica original" (Burity, 1997, p. 11). Como se depreende, a prática curricular a que nos estamos a referir produz-se sempre a partir da articulação com outras práticas, resultando na modificação de identidades originais.

Perante o que foi exposto, consideramos ser importante seguir um outro conceito de currículo que não se limite ao que é definido pelas determinações de políticas, mas que incorpore o que é criado por aqueles que o praticam, compreendendo que a prática curricular é resultado não só da atuação do professor isolado, mas das articulações que este estabelece com os demais sujeitos da escola e com as políticas que orientam o sistema educativo e esse currículo.

\section{A TEORIA Do Discurso ENQUANTO CAMINHO TEÓRICO-METODOLÓGICO}

Como atrás referimos, o estudo vincula-se à perspetiva da Teoria do Discurso (Laclau \& Mouffe, 2000) que aponta para um percurso teórico metodológico fundamentado na instabilidade da produção de sentidos, bem como na impossibilidade de fechamento último dos sentidos e de relação estrita entre significante e significado. A aproximação de Laclau e Mouffe com o movimento desconstrucionista de Derrida (1994) demonstra a indecidibilidade radical e a impossibilidade de que uma estrutura de significação possa encontrar, nela mesma, o seu próprio fechamento (Laclau, 1993). Nesta direção, ao analisarmos os sentidos de prática curricular nas produções da ANPEd, estamos à procura de uma fixação parcial do que é entendido por currículo praticado nessas pesquisas. Dessa forma, essa estrutura de significação - composta pelas publicações científicas - não poderá encontrar uma produção de sentido definitiva e estável, ou seja, como sustenta Lopes (2013), partimos por um caminho que admite a existência da imprecisão e da ambiguidade, e abandona os axiomas essencialistas.

A escolha por esse caminho teóricometodológico deve-se à compreensão de currículo enquanto movimento entre pensadovivido e ao entendimento de que os sentidos são construções parciais e nunca definitivas, o que impede a vinculação a uma perspetiva que tenha como intenção fechar a produção de sentidos. Clarificando, a Teoria do Discurso formulada por Laclau e Mouffe, ao demonstrar certas apropriações de Lacan, aponta para "o

\footnotetext{
${ }^{2}$ Desse modo, consideramos que prática curricular está associada ao conceito amplo de currículo que atravessa o artigo, compreendendo a ação dos professores no exercício de sua agência e processo de tomada de decisões face ao instituído. Distinguimos, portanto, a prática curricular da prática de ensino, sendo entendida esta enquanto atividade dos professores como ensinantes. Compreendemos que a prática curricular difere da prática docente, uma vez que a prática docente se refere às atividades inerentes a tudo o que decorre do exercício da profissão.
} 
permanente deslocamento do significado sob o significante" (Laclau, 1993, p. 7), isto é, para a "impossibilidade de fixação de sentido através de uma correlação estrita entre significante e significado" (p. 7).

Em síntese, afastamo-nos de uma totalidade fechada e estável entre significado e significante e inserimos o nosso objeto de pesquisa no campo da luta hegemónica, trazendo ainda uma noção de discurso que não distingue o linguístico do extralinguístico (Laclau, 1993). Compreendemos, deste modo, que a prática faz parte de uma realidade discursiva, pois "el carácter discursivo de un objeto no implica en absoluto poner su existencia en cuestion" (Laclau \& Mouffe, 2000, p. 115).

Afirmar o caráter discursivo de um objeto não significa colocar em questão a sua existência, como se disséssemos que tudo é discurso e, portanto, como se não existisse uma realidade material. Significa, sim, afirmar que os objetos só apresentam um sentido porque nós construímos esse sentido. Diante desta conceção, evidenciamos que "o sentido dos objetos do mundo físico não lhes é inerente" (Burity, 1997, p. 3); os sentidos são contingenciais, logo essenciais para compreender que não existe literalidade presa nas palavras e nas ações. Assim, ao trabalharmos com a noção de discurso como totalidade significativa em que a ação também está presente, partimos da ideia de que "a ação é inteiramente inerente ao discurso" (Burity, 2007, p. 76).

Tendo estas perspetivas por referência, trabalhamos com a prática curricular percebida na sua vinculação com a política, mas também na sua potencialidade recriadora, o que implica concebê-la, quer a partir das práticas articulatórias que constroem o seu caráter contingencial, quer das disputas de poder que formam o processo de significação do que é currículo planeado e do que é o currículo praticado, isto é, do que é o currículo planeado-vivido.

O percurso da pesquisa passou pela identificação dos textos académicos publicados na ANPEd e a sua leitura analítica. Para essa análise foram selecionados 33 trabalhos $\mathrm{e}$ 26 pósteres dos Grupos de Trabalho (GT) de formação de professores (GT-08) e de currículo (GT-12) que dizem respeito às reuniões do período compreendido entre 2006-2015, conforme pode ser visto na Tabela 1. Essa escolha optou por não excluir os pósteres, uma vez que a intenção foi identificar significantes que se articulassem com as práticas curriculares, independentemente das pesquisas estarem ou não concluídas. Considerámos todas as pesquisas, estivessem elas concluídas ou em andamento, que incorporam sentidos de práticas curriculares.

Numa fase inicial, procurámos encontrar nos resumos dos textos o significante prática curricular; contudo verificámos que, nesta parte dos textos publicados, ele quase não era mencionado. Verificámos também que os trabalhos selecionados não apresentavam uma definição deste significante, o que demonstra a importância de construir a sua definição a partir de práticas articulatórias com outros significantes. Perante esta constatação, decidimos procurar significantes que se articulassem com a nossa definição de prática curricular, tais como: currículo praticado, currículo em ação, praticantes do currículo, currículo vivido, currículo experienciado, currículo quotidiano. Quando percebíamos, nos resumos dos textos académicos publicados, a presença desses significantes, procurávamos a sua presença, lendo os trabalhos completos e analisando a argumentação a que estavam vinculados, para dessa forma selecionarmos os textos que mais se aproximavam da temática do currículo praticado.

Este procedimento permitiu-nos perceber 
TAB ELA 1

Pesquisas Sobre Prática Curricular Analisadas

\begin{tabular}{|c|c|c|}
\hline Reuniões/ano & Quantitativo de trabalhos analisados & Quantitativo de pósteres analisados \\
\hline 29a Reunião - 2006 & 3 & 4 \\
\hline $30^{\text {a }}$ Reunião - 2007 & 2 & 4 \\
\hline $31^{\text {a }}$ Reunião - 2008 & 5 & 3 \\
\hline $32^{\text {a }}$ Reunião - 2009 & 2 & 2 \\
\hline $33^{\text {a }}$ Reunião - 2010 & 4 & 2 \\
\hline $34^{\text {a }}$ Reunião - 2011 & 5 & 5 \\
\hline $35^{\text {a }}$ Reunião - 2012 & 3 & 0 \\
\hline $36^{\text {a }}$ Reunião - 2013 & 1 & 1 \\
\hline $37^{\text {a }}$ Reunião - 2014 & 8 & 5 \\
\hline $38^{\text {a }}$ Reunião - 2015 & 0 & 0 \\
\hline TOTAL & 33 & 26 \\
\hline
\end{tabular}

que os significantes vinculados à prática curricular eram mais frequentes no GT de currículo do que no GT de formação de professores, com a exceção dos trabalhos deste GT correspondente à $35^{\mathrm{a}}$ Reunião. Pudemos constatar também que nenhum dos trabalhos selecionados tinha como referencial teóricometodológico a Teoria do Discurso (Laclau \& Mouffe, 2000), embora fosse percebida a presença, em todas estas reuniões da ANPEd, de trabalhos com essa perspetiva. Contudo, estes tratavam das políticas curriculares, ou seja, do discurso enquanto texto, o que demonstra uma ausência de análises considerando o discurso enquanto prática. Assim, foi possível perceber, a partir dessa ausência, a existência de uma dificuldade em mobilizar a Teoria do Discurso em pesquisas sobre a prática, mesmo que esta perspetiva compreenda o discurso enquanto dimensão linguística e extralinguística.
3. As PRÁticas ARticulatórias NA CONSTRUÇÃO DO SIGNIFICANTE PRÁTICA CURRICULAR

A maioria dos trabalhos analisados, que focavam ou mencionavam a prática curricular, estavam inscritos no GT de currículo (GT-12) ${ }^{3}$ e apresentavam temáticas bastante diversas. Apesar de ter sido possível identificar a predominância de pesquisas que tratavam práticas curriculares vivenciadas no quotidiano das escolas, identificámos também outras que tratavam questões relacionadas com a recontextualização das políticas curriculares, com o currículo e a docência, com currículos praticados em cursos de formação de professores, com o currículo e o conhecimento, entre outros. Sendo o nosso objetivo compreender os sentidos de prática curricular construídos nas argumentações dos textos apresentados na ANPEd, para com isso tecermos sentidos de prática curricular, essa diversidade de focos foi mobilizada

\footnotetext{
${ }^{3}$ Dos 59 trabalhos analisados apenas um foi publicado no GT-08, de formação de professores.
} 
incorporando todos eles no nosso corpus de pesquisa.

Com a leitura e análise de todos estes textos, foi ainda possível perceber que não há uma definição clara do que seja prática curricular, já que eles não exemplificam quais são os elementos dessa prática, ou qual a diferença entre prática docente e prática curricular, nem o que tomam por currículo e por prática curricular. Entendemos que o objetivo das pesquisas apresentadas nas reuniões da ANPEd não era, talvez, fazer tal definição, embora, apesar disso, permitam compreender o que está a ser produzido sobre prática curricular e quais os sentidos que estão a ser construídos quando se fala em currículos em uso, currículos praticados, currículos vividos, e prática curricular. Com estes contributos, fomos desvelando os significantes trazidos nas argumentações dos autores, e, através das temáticas em foco nas suas pesquisas, os sentidos de prática curricular a que se vinculam.

Fomos percebendo que o significante prática curricular, articulado aos significantes referidos (quotidiano, conhecimento, currículo vivido, praticantes de currículo, criação curricular), demonstrava quais os sentidos de prática curricular que as pesquisas traziam. Para esta inferência, apoiamo-nos na ideia de que "o discurso que articula elementos ao mesmo tempo modifica suas identidades" (Burity, 1997, p. 11), o que significa dizer que as articulações produzidas pelas pesquisas entre o significante prática curricular e esses outros significantes foram responsáveis pela produção de mudanças das suas identidades originais. Na nossa perspetiva, a partir dessas mudanças é que pudemos ter acesso aos sentidos materializados nas produções científicas.

$\mathrm{Da}$ análise realizada, destacamos a recorrência ao significante quotidiano como centro de significação, o qual produz um sentido de prática curricular como criação e recriação do que acontece nas escolas e não como reprodução de uma política externa que incide nessas instituições. É possível ainda identificar, como referencial teórico nessas pesquisas, o recurso às perspetivas de Certeau (1998), as quais buscam delimitar sentidos de quotidiano como invenção do "homem" comum/ordinário. A perspetiva deste autor delimita, pois, a compreensão de que "os sujeitos praticantes deixam as suas marcas no quotidiano, vivem e fazem a vida acontecer" (Lyrio, 2010, p. 5, 33a Reunião da ANPEd) ${ }^{4}$. Assim, o quotidiano criado pelo "homem" comum é produto de suas marcas subjetivas, mas igualmente das marcas das subjetividades de outros tantos "homens" que do mesmo modo o criaram.

Nessa direção, os sujeitos que da escola fazem parte criam o quotidiano escolar a partir das impressões que deixam ao vivenciá-lo, ou seja, "nos espaçostempos escolares, professoras e alunos fazem da escola um lugar praticado" (Lyrio, 2010, p. 5, 33 a Reunião da ANPEd), sendo, portanto, cocriadores desse espaço. Ao mesmo tempo em que vivem, sentem e se movimentam no dia-a-dia da escola, eles também a fabricam, sendo, por isso, seus coautores e realizando essa construção a partir da coletividade.

\footnotetext{
${ }^{4}$ Fizemos a escolha de inserir nas referências o locus dos trabalhos, ou seja, o locus de enunciação do discurso, uma vez que colocamos as publicações analisadas no movimento discursivo com o nosso referencial teórico. Nesta análise utilizámos os trabalhos como produção científica, propondo um diálogo com os sentidos que apresentam. Isso significa dizer que eles estão de tal modo imersos na conceção que nos orienta que apenas é possível perceber a sua inclusão quando visualizamos as referências das citações no corpo do texto, onde, além do nome do autor, do ano e da página, incluímos o lugar da publicação. Desse modo, exemplificamos a nossa posição articulada aos sentidos retirados dos trabalhos, não de modo estanque, mas num movimento discursivo que permitiu incluí-los como produção de conhecimento científico.
} 
Em síntese, os professores assumem papel de destaque nessa fabricação, mas relacionados com os demais sujeitos que compõem a escola, admitindo que um quotidiano produzido em conjunto não se constitui apenas enquanto reprodução das políticas curriculares; embora também o seja, ele é uma construção criativa daqueles que compõem as instituições escolares. Essa construção criativa é possibilitada pelas táticas, conceito desenvolvido por Certeau (1998) e presente nas pesquisas analisadas, as quais indicam outros caminhos possíveis a serem seguidos ou desenvolvidos pelos professores que extrapolam as definições das políticas ou das determinações das instâncias educativas hierarquicamente superiores aos professores.

A tática é movimento dentro do campo de ação do inimigo, como dizia von Bullow, e no espaço por ele controlado. Ela não tem, portanto, a possibilidade de dar a si mesma um projeto global nem de totalizar o adversário num espaço distinto, visível e objetivável. Ela opera golpe por golpe, lance por lance. Aproveita as ocasiões e delas depende, sem base para estocar benefícios, aumentar a propriedade e prever saídas. $\mathrm{O}$ que ela ganha não se conserva. Este não-lugar lhe permite sem dúvida mobilidade, mas numa docilidade aos azares do tempo, para captar no vôo as possibilidades oferecidas por um instante. Tem que utilizar, vigilante, as falhas que as conjunturas particulares vão abrindo na vigilância do poder proprietário. Aí vai caçar. Criar ali surpresas. Consegue estar onde ninguém espera. É astúcia. (Certeau, 1998, pp. 100101)

Os professores submetidos às políticas curriculares criam no quotidiano as possibilidades de ruturas, produzindo uma prática que situa o currículo entre o instituído pelas políticas e o que é identificado como necessário face aos contextos e situações onde ele vai ser vivido. É, pois, operando na falha da tentativa de totalização das políticas que as táticas são construídas pelos professores dentro da aparente repetição do quotidiano, o qual esconde nas suas fraturas as marcas do novo.

Aceitando que as táticas possibilitam a criação do novo, é possível que o quotidiano também demonstre a emergência de teorias e práticas criadas e recriadas nos processos de organização e de desenvolvimento do currículo. Dessa maneira, o quotidiano escolar é visto nas pesquisas como

o espaço que dá transparência - com os limites da imediaticidade - à relação da prática e da teoria. O cotidiano escolar é uma espécie de bumerang, que devolve elementos e aspectos de uma mesma realidade, mas não são autocompreensivas em sua dimensão empírica. Consideramos que o espaço escolar cotidiano é diáfano, potencialmente enriquecedor de análise e de elaboração de teorias. (Torriglia, 2008, p. 15, 31 a Reunião da ANPEd)

Articulada com o quotidiano, a prática curricular constitui-se como espaço em que teoria e prática se revelam, e em que a teoria não é transposta para a realidade, mas, sim, traduzida pelos professores no currículo praticado-vivido. Ou seja, é traduzida nas escolhas que estes realizam para selecionar o conhecimento ensinado, na forma como planificam, nas decisões que tomam sobre o que avaliar, na organização do tempo e dos objetivos pedagógicos que traçam.

A partir do significante quotidiano, os trabalhos também veem na prática curricular a possibilidade da produção de teorias de educação, nascidas do potencial criador daqueles que praticam o currículo. Estas teorias, traduzidas nos modos de saber e fazer dos professores, estão também inscritas nas demandas das políticas curriculares e nas demandas dos outros sujeitos da escola, influenciando novas formas de ser e estar na docência. Desse modo, as práticas curriculares 
inscrevem-se dentro das "possibilidades imprevisíveis [que] acontecem em todos os espaços-tempos escolares, num processo dialógico contínuo e interminável de negações, negociações, rupturas, desconstruções, buscas, invenções, coletividade, complexidade, pluralidade, cooperação, transformação" (Kretli, 2007, p. 16, 30ª Reunião da ANPEd). Infere-se, pois, que esta negociação ocorre entre o instituinte e o instituído, ou seja, entre a normatização das políticas e as suas traduções realizadas por aqueles que compõem a escola.

As pesquisas apresentadas nos textos analisados parecem, pois, apontar para o facto de que, se há currículo enquanto texto, há também a sua negociação no currículo praticado. Apontam também para uma rutura com o instituído, evidenciada pelas "linhas de fratura por onde vazam as possibilidades e potencialidades de se tecer outros pensamentos e concepções" (Chiquito \& Eyng, 2008, p. 15, 31 a Reunião da ANPEd) que, consequentemente, podem fabricar outros modos de se fazer currículo. Nesse sentido, trata-se de

fazer o movimento, traçar a linha de fuga em toda a sua positividade, ultrapassar um limiar, atingir um continuum de intensidades que não valem mais do que por elas mesmas, encontrar um mundo de intensidades puras, onde todas as formas se desfazem, todas as significações também. (Deleuze \& Guattari, 1977, p. 20)

Em síntese, consideramos importante focar a atenção em movimentos de fabricação do novo, isto é, olhar para os currículos que estão sendo agora produzidos nas escolas, que estão ultrapassando os limites do instituído, e que estão rompendo com as fronteiras das políticas e inventando outras formas de viver e criar práticas curriculares. Essa é igualmente uma dimensão sinalizada nas pesquisas e que aponta para a necessidade de evidenciar o que as escolas estão produzindo em termos de currículo, ou seja, de fazer emergir o que quotidianamente está sendo produzido, mas que em muitos casos ainda permanece submerso na ideia de que esses espaços escolares são apenas loci de reprodução e não de criação. Secundamos, com as publicações científicas, que "os movimentos instituintes precisam ser mais reconhecidos do que as pressões políticas, econômicas, sociais, que desqualificam, engessam e prescrevem as ações dos professores e alunos, eximindoos de sua vitalidade, de sua participação, da coletividade" (Kretli, 2009, p. 5, 32a Reunião da ANPEd).

As pesquisas que constituíram objeto de estudo demonstram a necessidade de se desvelar a pluralidade dos currículos praticados pelos professores, currículos esses marcados pelas influências das políticas curriculares nacionais e locais, pelas práticas dos demais membros da escola, e pelas subjetividades dos próprios professores, uma vez que "ao dialogarmos com as experiências significativas dos sujeitos reais das escolas, temos chance de efetivamente produzir mudanças emancipatórias, com possibilidades de escolhas sociais e políticas mais justas e felizes" (Kretli, 2009, p. 12, 32 a Reunião da ANPEd).

Reforçando o que já indiciámos, nas publicações analisadas, as práticas curriculares ganham corpo como diálogo contínuo entre políticas curriculares e interpretação dessas políticas; como negociação entre o que o professor deseja fazer e o que a escola espera que ele faça; como cooperação entre os professores e seus pares, mas também entre professores e alunos, e entre professores e órgãos de gestão, uma vez que "pensar em currículos praticados é pensar que o currículo é tecido com a contribuição de cada indivíduo que por si só constitui os seus próprios currículos, tecendo-os nos seus cotidianos" 
(Silva, Rosa, \& Costa, 2009, p. 4, 32a Reunião da ANPEd). Essas pesquisas reconhecem também o currículo praticado como produção plural, isto é, reconhecem que a prática curricular de um professor de uma instituição específica será diferente daquela que é fabricada por outro professor, mesmo dentro da mesma instituição, porque a tradução que é feita das políticas curriculares e a influência de outros membros da escola, a que são sujeitos, têm efeitos distintos. Como refere um dos estudos: "sujeitos de culturas diferentes desenvolvem práticas curriculares diferenciadas, inscritas nas possibilidades de circularidade entre as culturas (Ginzburg, 1986) expressas nas propostas e normas curriculares e as suas próprias, de formação individual e coletiva" (Garcia \& Süssekind, 2010, p. 6, 33ª Reunião da ANPEd).

Em resumo, a articulação produzida nas pesquisas entre práticas curriculares e quotidiano apresenta a escola como lugar de possibilidades, apontando para a necessidade de evidenciar o que de facto se está a materializar em seu espaçotempo, ao contrário de apenas dizer à escola como ela deve ser. Para além disso, os textos reconhecem e devolvem ao professor o protagonismo da criação curricular, desinvisibilizando as práticas cotidianamente vividas.

A escola aparece nos estudos nosdoscom os cotidianos, em geral, e nos textos citados para além da idéia muito difundida de mera reprodutora do aparelho ideológico do estado e das injustiças sociais. Ela não se resume a um aparato disciplinar estático. Os professores não são, sempre, os 'exterminadores do futuro', mas, pelo contrário, são eles que sabem, fazem e relatam. (Cinelli \& Garcia, 2008, p. 14, 31 a Reunião da ANPEd)

Além da articulação com o quotidiano, estes textos científicos também produzem práticas articulatórias com o significante conhecimento, sem no entanto reduzir o sentido de currículo a uma listagem de conhecimentos a serem aprendidos na escola e a prática curricular ao seu ensino. Pelo contrário, colocam o conhecimento como uma das dimensões do currículo, sendo selecionado e organizado pelos professores nas suas práticas curriculares. Dito de outro modo, o conhecimento é visto nas pesquisas como "captura do movimento no real, é a unidade da teoria e da prática na busca da transformação, de novas sínteses no plano do pensamento e na realidade histórica" (Torriglia, 2008, p. 4, 31 a Reunião da ANPEd). Isso significa dizer que o conhecimento, como movimento, não se fixa de uma vez por todas, mas busca responder às questões de determinado tempo histórico, sendo condição humana a necessidade por conhecer.

Partindo desse sentido, as pesquisas demonstram certa preocupação com o conhecimento selecionado e organizado pelos professores nas suas práticas curriculares, compreendendo que ele está demasiadamente voltado para uma ideia de utilidade, ou seja, para aquilo que é considerado de utilidade para o mercado de trabalho.

O conhecimento trabalhado na sala de aula aparece como deslocado do tempo e do espaço e preso a um cotidiano escolar passado. Esse aparente deslocamento, no entanto, pode refletir o esforço docente para acompanhar as demandas sociais. No contexto geral das práticas curriculares observadas, o que vemos é um conhecimento escolar empobrecido, destituído de sentido, deslocado, fragmentado e, principalmente, incapaz de auxiliar na constituição de uma compreensão crítica do mundo. (Lunardi, 2007, p. 12, 30ª Reunião da ANPEd)

Esse entendimento do conhecimento, revelado nas pesquisas, advém das políticas curriculares 
que buscam controlar o que se ensina nas escolas, fechando a possibilidade da produção de conhecimento pelos professores e seus alunos dentro de uma realidade contextual, como pode ser percebido na proposta da BNCC5. Apesar dessa preocupação sinalizada pelas pesquisas, elas também demonstram a possibilidade de os professores, nas suas práticas curriculares, visibilizadas pelos estudos nos/dos/com os quotidianos, criarem conhecimentos que não necessariamente se enquadrem nos modelos propostos pelas políticas curriculares, mas respondam às urgências sentidas pelo exercício da docência. A necessidade de se ter "respeito aos cotidianos como espaçotempo de invenção permanente de conhecimentos e a convicção de que os professores, nas escolas em que atuam, são grandes inventores de conhecimentos e, como tal, têm muito a dizer sobre suas vivências e criações" (Caldas, 2010, p. 3, 33a Reunião da ANPEd) são evidenciadas. Ou seja, as pesquisas nos/dos/com os quotidianos buscam devolver aos professores o papel de intelectuais responsáveis pela organização do processo didático-pedagógico inerente às práticas curriculares, sendo um dos referenciais recorrentes.

Este facto evidencia que os estudos sobre prática curricular têm como intenção inverter a postura metodológica que olha a escola como lugar das ausências para passar a compreendêla no seu potencial criativo e criador, e onde é possível encontrar "a esperança, a vontade de fazer, a criação de possibilidades, a busca de alternativas, a discussão, a memória de tantas propostas feitas e desfeitas, a crença na utopia” (Macedo, Oliveira, Manhães, \& Alves, 2011, p. 17).

Essa possibilidade de criação igualmente demonstra, conforme foi anteriormente afirmado, que o conhecimento não está dado de uma vez por todas, mas sim que ele se cria e recria nas ações do quotidiano. Visto dessa forma, diminui-se a distância entre conhecimento, professores e alunos, produzindo-se formas mais democráticas de viver o currículo. Compreendemos, então, que, diferentemente do que pensava a corrente da modernidade, a perspetiva dos estudos nos/dos/ com os quotidianos percebe que existem modos de se produzir conhecimentos que ultrapassam os espaços das universidades, entrando nas "dobras de tecido que vão se desdobrando, se arrumando, desarrumando, e que estão presentes nos/dos/com os cotidianos das escolas, e nos seus currículos praticados" (Oliveira, 2008, p. 14, 31 a Reunião da ANPEd). É neste sentido que os conhecimentos se inscrevem nas necessidades dos sujeitos que estão aprendendo, na relevância social do seu ensino, na possibilidade de inserirem professores e alunos no processo de produção de novos saberes e fazeres.

Talvez tendo essa ideia por referência, as pesquisas consideram ser "necessária uma prática pedagógica comprometida com uma educação transformadora, a qual implica a busca, no nível local, de possibilidades de ruptura dentro das políticas curriculares, em um movimento de contra-hegemonia e de ressignificação dos conhecimentos" (Negri \& Souza, 2008, p. 3, 31 a Reunião da ANPEd). Esta ressignificação não pressupõe o esquecimento dos conhecimentos historicamente produzidos, mas antes a inserção nas práticas curriculares de conhecimentos que façam sentido para os sujeitos que estão na condição de aprendizes, ou seja, que os façam compreender a sua realidade. Além disso, a rutura da política também não significa ignorar as suas demandas, mas considerar o que o contexto local da escola está a produzir em termos de conhecimento.

\footnotetext{
${ }^{5}$ Estamos a referir-nos à Base Nacional Curricular Comum (BNCC), aprovada no Brasil na sua terceira versão em abril de 2017, que lista o que deve ser ensinado em termos de conteúdos nas escolas, como referência única, freando os projetos contextualizados das escolas.
} 
Em paralelo com a possibilidade de criação do conhecimento nas práticas curriculares dos professores está a necessidade de tornar conhecido esse processo de criação que responde a alguma demanda do quotidiano escolar. Para isso as produções científicas sinalizam que

\begin{abstract}
O importante em se olhar e descrever uma prática como essa é trocar com os outros professores e leitores para que eles também se vejam como possíveis realizadores de práticas como essas, cujos resultados podem ser identificados como sendo de alta contribuição para engendrar subjetividades transformadoras e democráticas. Nessas ocasiões, os conhecimentos são recriados e desinvisibilizados mostrando outros jogos de poder e de verdade [que] são testados cotidianamente reinventando as táticas de sobrevivência de saberes não hegemônicos. (Cinelli \& Garcia, 2008, p. 12, 31 ${ }^{\text {a }}$ Reunião da ANPEd)
\end{abstract}

Concluindo, as produções científicas analisadas evidenciam a necessidade de investigar as práticas curriculares que estão a ser produzidas nas escolas para que outros agentes educativos, que compõem outros espaços escolares, tenham acesso aos processos de criação e recriação do currículo, e assim possam eles também ser agentes (Leite \& Fernandes, 2010; Priestley et al., 2015) desse processo de invenção e reinvenção. Esta é também uma das razões porque atribuímos relevância ao estudo realizado e de que este artigo dá conta.

\section{ALgUMAS CONSIDERAÇÕES FINAIS}

Retomando o objetivo da pesquisa, que identificou sentidos atribuídos ao significante prática curricular nas produções científicas da ANPEd, percebeu-se, pela análise dos textos que constituiram o seu corpus, que o currículo praticado está a ser fabricado numa relação entre propostas curriculares advindas das políticas e propostas criadas e recriadas pelos professores no quotidiano das escolas. Foi identificado um sentido de prática curricular que concebe a escola e os professores como produtores de currículo e não apenas como reprodutores de demandas de instâncias superiores. Deste modo, o currículo praticado é visto enquanto espaço no qual múltiplas demandas disputam a hegemonização de um sentido particular, demandas essas que advêm não só das políticas enquanto textos, mas também dos professores nas práticas curriculares fabricadas no quotidiano. Sendo assim,

a escola não é tida como espaço de implementação de propostas construídas em outros contextos de produção de currículo. A escola é uma das instâncias de produção curricular que se articula às demais instâncias, sendo influenciada por estas ao mesmo tempo em que as influencia. (Penteado, 2015, p. 37)

Diante do exposto, na produção de significação estudada, percebemos que os textos analisados vinculam o sentido de prática curricular ao de política, articulam a prática curricular com o sentido de produção cotidiana, bem como demonstram que os professores também são autores do currículo. Neste sentido, a leitura e a análise das pesquisas divulgadas na ANPEd permitem-nos delimitar os sentidos das práticas curriculares, mas numa delimitação que não satura as suas identidades.

Por fim, demonstramos ainda como os estudos baseados em perspetivas discursivas, tal como o presente artigo, podem contribuir para as pesquisas sobre currículo, "uma vez que possibilitam a compreensão de que não existe um sentido único e fechado sobre ele, ajudando ainda a demonstrar como se materializam as lutas hegemónicas nas quais esses sentidos se 
inscrevem para sobressairem sobre outros" (Silva, Melo, Carmo, \& Almeida, 2016, p. 13). A partir da Teoria do Discurso, evidenciamos como as regularidades demarcam os sentidos de currículo e das práticas curriculares, e ainda como as singularidades ajudam a evidenciar essa não saturação e a possibilidade de existência de outros sentidos.

\section{REFERÊNCIAS}

Arroyo, M. (2013). Currículo, território em disputa. Petrópolis, RJ: Vozes.

Burity, J. (1997). Desconstrução, hegemonia e democracia: O pós-marxismo de Ernesto Laclau. Recife: Fundaj.

Burity, J. (2007). Teoria do discurso e análise do discurso: Sobre política e método. In S. Weber \& T. Leithäuser (Eds.), Métodos qualitativos nas ciências sociais e na prática social (pp. 73-83). Recife: Ed. UFPE.

Caldas, A. (2010, outubro). Práticas cotidianas de pesquisar e praticar currículos: Jornal eletrônico e a circulação de conhecimentos. Texto apresentado no GT 12 na 33a Reunião da ANPED, Caxambu, Brasil. Disponível em http://33reuniao.anped.org.br/33encontro/ app/webroot/files/file/Trabalhos $\% 20$ em\%20PDF/GT12-6984--Int.pdf

Carmo, P., \& Almeida, L. (2014). As contribuições do eixo curricular pesquisa e prática pedagógica no currículo pensado do curso de Pedagogia. Revista FAFIRE, 7(1), 22-34.

Certeau, M. (1998). A invenção do cotidiano: Artes de fazer. Petrópolis, RJ: Vozes.

Chiquito, R., \& Eyng, A. M. (2008, outubro). Escrita curricular: Algumas considerações a partir das abordagens pós-estruturalistas/ pós-críticas do currículo. Texto apresentado no GT 12 na $31^{\text {a }}$ Reunião da ANPEd, Caxambu, Brasil. Disponível em http:// www.anped.org.br/sites/default/files/gt124687-int.pdf

Cinelli, M. L., \& Garcia, A. (2008, outubro).
Olhar sem ver: Escolas invisíveis e currículos praticados. Texto apresentado no GT 12 na $31^{\text {a }}$ Reunião da ANPED, Caxambu, Brasil. Disponível em http://www.anped.org.br/ sites/default/files/gt12-4443-int.pdf

Deleuze, G., \& Guattari, F. (1977). Kafka: Por uma literatura menor. Rio de Janeiro: Imago.

Derrida, J. (1994). Espectros de Marx. O estado da dívida, o trabalho do luto e a nova Internacional. Rio de Janeiro: RelumeDumará.

Ferraço, C., \& Nunes, K. (2012). Currículos, culturas e cotidianos escolares: Afirmando a complexidade e a diferença nas redes de conhecimento dos sujeitos praticantes. In C. Ferraço, \& J. Carvalho (Eds.), Currículos, pesquisas, conhecimentos e produção de subjetividades (pp. 71-102). Petrópolis, RJ: DP et Alii; Vitória, ES: Nupec/UFES.

Garcia, A., \& Süssekind, M. L. (2010, outubro). Práticas de currículos-composição: Desinvisibilizando currículos e políticas nos cotidianos da formação docente. Texto apresentado no GT 12 na $33^{a}$ Reunião da ANPEd, Caxambu, Brasil. Disponível em http://33reuniao.anped.org.br/33encontro/ app/webroot/files/file/Trabalhos $\% 20$ em\%20PDF/GT12-6595--Int.pdf

Gonçalves, C. (2017). Práticas avaliativas de estudantes-professoras: Desenvolvimento da profissionalidade e profissionalismo a partir dos contextos de influência presentes no cotidiano escolar (Dissertação de mestrado). UFPE - CAA, Caruaru, Brasil.

Hagemeyer, R. (2011). Currículo e mudança: Práticas mediadoras como catálise, ultrapassagens e referências para a formação docente na contemporaneidade. Currículo Sem Fronteiras, 11(1), 232-251.

Kretli, S. (2007, outubro). Artefatos culturais usados por professores/as e alunos/as no cotidiano escolar como possibilidades de ressignificar o currículo. Texto apresentado no GT 12 na 30 a Reunião da ANPEd, Caxambu, Brasil. Disponível em http:// 
www.anped.org.br/sites/default/files/gt123217-int.pdf

Kretli, S. (2009, outubro). Burlas e artimanhas de professores e alunos: Tecendo redes de saberes, valores e pensamentos... O currículo praticado nas escolas. Texto apresentado no GT 12 na 32a Reunião da ANPEd, Caxambu, Brasil. Disponível em http://32reuniao. anped.org.br/arquivos/trabalhos/GT125505--Int.pdf

Laclau, E. (1993). Discourse. In R. Goddin, \& P. Pettit (Eds.), The Blackwell companion to contemporary political philosophy (pp. 541547). Oxford: Blackwell.

Laclau, E., \& Mouffe, C. (1987). Hegemonía y estrategia socialista: Hacia una radicalización de la democracia. Madrid: Letra.

Laclau, E., \& Mouffe, C. (2000). Posmarxismo sin pedido de disculpas. In E. Laclau, Nuevas reflexiones sobre la revolución de nuestro tempo (pp. 111-145). Buenos Aires: Nueva Visión.

Leite, C.(2002). Ocurrículoeo multiculturalismo no sistema educativo português. Lisboa: Fundação Calouste Gulbenkian.

Leite, C., \& Fernandes, P. (2010). Desafios aos professores na construção de mudanças educacionais e curriculares: Que possibilidades e que constrangimentos?. Educação, 33(3), 198-204.

Leite, C., Fernandes, P., \& Mouraz, A. (2014). Curriculum contextualization: A comparative analyses of meanings expressed in Portuguese and English school evaluation. Studies in Education Evaluation, 43, 133-138.

Leite, C., Gomes, L., \& Fernandes (2001). Projectos curriculares de escola e de turma: Conceber, gerir e avaliar. Porto: Edições ASA.

Libâneo, J. C. (2003). Educação escolar: Políticas, estrutura e organização. São Paulo: Cortez.

Lopes, A. C. (2013). Teorias pós-críticas, política e currículo. Educação, Sociedade \& Culturas, 39, 7-23.
Lunardi, G. (2007, outubro). Ainda as "partes da árvore": Seleção, organização e distribuição do conhecimento na sala de aula nas séries iniciais do ensino fundamental. Texto apresentado no GT 12 na 30a Reunião da ANPEd. Disponível em http://www.anped. org.br/sites/default/files/gt12-3802-int.pdf

Lyrio, K. (2010, outubro). O currículo por projetos na educação infantil: Sobre as negociações, traduções e burlas. Texto apresentado no GT 12 na $33^{\text {a }}$ Reunião da ANPEd, Caxambu, Brasil. Disponível em http://33reuniao.anped.org.br/33encontro/ app/webroot/files/file/Trabalhos $\% 20$ em\%20PDF/GT12-6437--Int.pdf

Macedo, E., Oliveira, I. B., Manhães, L. C. L., \& Alves, N. (Eds). (2011). Criar currículo no cotidiano. São Paulo: Cortez.

Moreira, A. F. (1995). O currículo como política cultural e a formação docente. In T. T. da Silva, \& A. F. Moreira (Eds.), Territórios contestados: O currículo e os novos mapas políticos e culturais. Petrópolis, RJ: Vozes.

Moreira, A. F. (2001). Para quem e como se escreve no campo do currículo? Notas para discussão. Revista Portuguesa de Educação, 14(1), 73-93.

Negri, S., \& Souza, M. I. (2008, outubro). Afinal, existe um currículo democrático? Texto apresentado no GT 12 na $31^{\text {a }}$ Reunião da ANPEd, Caxambu, Brasil. Disponível em http://31reuniao.anped.org.br/1trabalho/ GT12-4338--Int.pdf

Oliveira, M. (2008, outubro). Uniformes entre imagens do pensamento e narrativas dos meus cotidianos. Texto apresentado no GT 12 na $31^{\text {a }}$ Reunião da ANPEd, Caxambu, Brasil. Disponível em http://www.anped. org.br/sites/default/files/gt12-4497-int.pdf

Pacheco, J. (2005). Escritos curriculares. São Paulo: Cortez.

Penteado, L. (2015). Entre dizeres, saberes e fazeres: Os espaços vivenciados pelo ensino religioso no currículo da escola pública em Recife no período de 1996 a 2014 (Dissertação de mestrado). UFPE, Recife. 
Priestley, M. (2011). Schools, teachers, and curriculum change: A balancing act? Journal of Educational Change, 12(1), 1-23.

Priestley, M., Biesta, G., \& Robinson, S. (2015). Teacher agency: What is it and why does it matter?. In R. Kneyber, \& J. Evers (Eds.), Flip the system: Changing education from the bottom up (pp. 134-148). London: Routledge.

Silva, M. A., \& Almeida, L. (2013). A produção discursiva curricular no terreno da formação docente: Sentidos em disputa. Revista FAFIRE, 6(2), 98-107.

Silva, M. A., Melo, M. J. C., Carmo, P. M., \& Almeida, L. A. A. (2016). Aproximações entre a análise de discurso e os estudos curriculares: Um olhar a partir das pesquisas em educação no agreste pernambucano. Texto apresentado no eixo 1 no VI EPEPE, Juazeiro, Brasil. Disponível em http://www.fundaj.gov.br/ index.php?option=com content\&view= article\&id $=5019 \&$ Itemid $=1141$

Silva, T., Rosa, R., \& Costa, S. (2009, outubro). A trajetória de um professor negro na universidade - Questões culturais e currículo. Texto apresentado no GT 12 na 32a Reunião da ANPEd, Caxambu, Brasil. Disponível em http://32reuniao.anped.org.br/arquivos/ posteres/GT12-5703--Int.pdf

Tardif, M. (2002). Saberes docentes e formação profissional. Petrópolis, RJ: Vozes.

Torriglia, P. (2008, outubro). Organização escolar: O currículo como uma mediação do conhecimento. Texto apresentado no GT 12 na $31^{\text {a }}$ Reunião da ANPEd, Caxambu, Brasil. Disponível em http://www.anped.org.br/ sites/default/files/gt12-4254-int.pdf

\section{MeAnings ATtRiBUted TO THE SIGNIFICANT CURRICULAR PRACTICE IN SCIENTIFIC PRODUCTIONS IN THE A NPED}

\section{Abstract}

The article is part of the debate about the curriculum, specifically about the curricular practices, and aims to identify meanings attributed to the significant curricular practice in the scientific productions of ANPEd (National Association of Postgraduate and Research in Education), Brazil. To that end, it mobilizes curriculum concepts that understand it as a formative project produced by the policies and by the educational agents who configure and practice it in everyday school life recognizing it as a disputed territory. Taking this in consideration, we selected, read and analyzed the studies that were limited to the period 2006-2015, based on Ernesto Laclau and Chantal Mouffe's Discourse Theory. This analysis allowed us to identify an articulation of curricular practice with other signifiers, configuring meanings that recognize the daily life of schools as spaces of curricular creation and re-creation, and that regard teachers as intellectuals responsible for organizing the didactic-pedagogical process, i.e., as capable of creating knowledge that does not necessarily fit into the models proposed by curricular policies, but respond to the urgencies felt by the teachers.

Keywords: Senses; Curriculum; Curricular Practice; Discourse Theory 


\section{SENTIDOS \\ ATRIB U I D O S \\ A L} SIGNIFICANTE PRÁCTICA CURRICULAR EN LAS PRODUCCIONES CIENTÍFICAS DE LA ANPED

\section{RESUMEN}

El artículo se inscribe en el debate sobre el currículo, y más específicamente sobre las prácticas curriculares, y tiene como objetivo identificar sentidos atribuidos al significante práctica curricular en las producciones científicas de la ANPEd (Asociación Nacional de Postgrado e Investigación en Educación), Brasil. Para ello, moviliza conceptos de currículo que lo comprenden como proyecto formativo producido por las políticas y por los agentes educativos que lo configuran y practican en los cotidianos escolares, reconociéndolo aún como territorio de disputas. Frente a esa comprensión, seleccionamos, leemos en su totalidad $y$ analizamos las investigaciones circunscritas al período 2006-2015 a partir de una perspectiva basada en la Teoría del Discurso de Ernesto Laclau y Chantal Mouffe. Este análisis permitió identificar una articulación de la práctica curricular con otros significantes, configuradora de sentidos que reconocen los cotidianos de las escuelas como espacios de creación y recreación curriculares, o sea, que consideran esas instituciones no más como lugares de ausencias, y que contemplan a los profesores como intelectuales responsables de la organización del proceso didácticopedagógico, capaces de crear conocimientos que no necesariamente se encuadren en los modelos propuestos por las políticas curriculares, sino que respondan a las urgencias sentidas por el ejercicio de la docencia.

Palabras Clave: Sentidos; Currículo; Práctica Curricular; Teoría del Discurso

\footnotetext{
${ }^{\text {I }}$ Programa de Pós-Graduação em Educação, Universidade Federal de Pernambuco, Brasil.

II Programa de Pós-Graduação em Educação, Universidade Federal de Pernambuco, Brasil.

III Centro de Investigação e Intervenção Educativas (CIIE), Faculdade de Psicologia e de Ciências da Educação, Universidade do Porto, Portugal. ORCID: 0000-0001-9960-2519.
}

Toda a correspondência relativa a este artigo deve ser enviada para:

Maria Júlia Carvalho de Melo

Rua Bom Jesus, n 33, Bairro São Francisco, CEP 55008030

Recebido em janeiro de 2018

Caruaru, Pernambuco, Brasil.

E-mail: melo.mariajulia@gmail.com 